\title{
Examining the Differences of Hong Kong and Taiwan Students' Performance on the Number Sense Three-tier Test
}

\author{
Ka Luen Cheung ${ }^{1}$, Der-Ching Yang ${ }^{2 *}$ \\ ${ }^{1}$ The Education University of Hong Kong, Hong Kong, CHINA \\ ${ }^{2}$ National Chiayi University, Chiayi City, TAIWAN \\ Received 3 February 2018 - Revised 11 April 2018 - Accepted 12 May 2018
}

\begin{abstract}
Assessing elementary students' performance on number sense provides early predictors and support for interventions in teaching and learning number sense before children fall seriously behind in school. There is no study that concerns the differences between Hong Kong and Taiwan students' performance on the number sense threetier test. The purposes of this study were to examine the differences of Hong Kong and Taiwan students' performance on the number sense three-tier test and the possible misconceptions. A total of 125 fifth graders, 942 sixth graders from Hong Kong, and 819 fifth graders from Taiwan participated in this study. Results show that there are significant differences on the performance of first two-tier test and confidence between the fifth graders of HK and Taiwan, sixth graders of HK and fifth graders of Taiwan, respectively. Strong misconceptions and key differences among the HK fifth graders, HK sixth graders, and Taiwan fifth graders were found and discussed.
\end{abstract}

Keywords: Hong Kong, number sense, Taiwan, three-tier test

\section{INTRODUCTION}

Many studies highlighted that number sense (NS) should play an important role in school mathematics teaching and learning internationally (Berch, 2005; Dunphy, 2007; Griffin, 2004; Jordan, Glutting, Ramineni, \& Watkin, 2010; Lin, Yang, \& Li, 2016; McIntosh, Reys, \& Reys, 1992; National Council of Teachers of Mathematics [NCTM], 2000; Sowder, 1992; Yang \& Li, 2013). In addition, number sense also plays a key role in our daily life (Dehaene, 1997; Yang, \& Wu, 2010). Therefore, helping children develop number sense has been emphasized internationally by many researchers and reports (Australian Education Council, 1991; Berch, 2005; Dunphy, 2007; Jordan, Glutting, \& Ramineni, 2010; Jordan, Kaplan, Locuniak, \& Ramineni, 2007; McIntosh, Reys, Reys, Bana, \& Farrel, 1997; Sood \& Jitendra, 2007; Verschaffel, Greer \& De Corte, 2007; Yang, \& Li, 2013; Yang, \& Wu, 2010). Earlier studies argued that lack of number sense often leads to learning disabilities in mathematics to a certain degree (Dyson, Jordan, \& Glutting, 2013; Jordan et al., 2007, 2010). If students are able to exercise number sense flexibly, it will help them keep learning effects longer (Jordan et al., 2010; Yang, Li, \& Lin, 2008). This shows the importance of number sense.

Hong Kong and Taiwan students performed very well on international mathematics assessments, such as The Trends in International Mathematics and Science Study (TIMSS) 2015 (Mullis, Martin, Foy, \& Hooper, 2016) and The Programme for International Student Assessment (PISA) 2015 (Organization for Economic Co-operation \& Development [OECD], 2016). However, these international mathematics assessments didn't focus on students' reasons, misconceptions, and confidence on number sense, though the studies examined students' performance on number domain. Assessing number sense [including students' reasons, misconceptions, and confidence] is crucial to the teacher to see students' understanding of numbers and its operation (Akkaya, 2016; Şengül \& Gülbağc1, 2014; Yang, \& Li, 2013; Yang, \& Wu, 2010). The screening test of students' performance on number sense can be used to provide early predictors and support for interventions in teaching and learning number sense before children fall seriously behind in school (Gersten, Jordan, \& Flojo, 2005; Jordan et al., 2010). In addition, previous studies revealed that secondary school students experience difficulties on number sense (Şengül, \& Gülbağcl, 2012, 2014). By assessing elementary students' performance and misconceptions on number sense, this study provides the results

(C) 2018 by the authors; licensee Modestum Ltd., UK. This article is an open access article distributed under the terms and conditions of the Creative Commons Attribution License (http://creativecommons.org/licenses/by/4.0/). $\square$ kaluen@eduhk.hk $\square$ dcyang@mail.ncyu.edu.tw (*Correspondence) 


\section{Contribution of this paper to the literature}

- Hong Kong $5^{\text {th }}$ and $6^{\text {th }}$ grade and Taiwan $5^{\text {th }}$ grade students do not perform well on number sense as compared to their performance on international mathematics assessments (e.g. PISA and TIMSS).

- HK $5^{\text {th }}$ and $6^{\text {th }}$ grade students are not only significantly performed better on NS both-tiers test than Taiwan $5^{\text {th }}$ grade students, but also are more confident in answering NS two-tiers test than Taiwan $5^{\text {th }}$ grade students.

- Key differences on the number sense performance and misconceptions between HK and Taiwan students exist.

of students' performance and possible misconceptions on number sense. The Authors believes that it would be beneficial for the teacher to address a preliminary strategy and teaching development in elementary grades in order to improve students' ability on number sense when they look forward to attending secondary schools. These notions motivated the authors to assess the elementary students' performance on number sense.

The results of students' performance on number sense are also crucial and challenging to the curriculum designers in a country, in which the results could be a reflection and consideration for developing and improving the curriculum standards. If we look at the mathematics curricula in Hong Kong and Taiwan, the curricula have highlighted the needs of instruction for developing students' number sense: (1) the reforms in the school mathematics curriculum in Hong Kong have emphasized the needs for teachers to provide instructions that lead to conceptual understanding for students to develop number sense and teacher should carry out activities to foster number sense (Hong Kong Curriculum Development Council and the Hong Kong Examinations and Assessment Authority, 2014) and (2) Taiwan's major mathematics curriculum reforms have highlighted that mathematics instruction should help children in developing number sense skills (Ministry of Education in Taiwan, 2017). Moreover, The NS study at Hong Kong is the first systematic study in number sense of students in Hong Kong. However, their performance is not as good as what has been seen from the other international assessment tests in mathematics. It would be of interest to compare their results with Taiwan, a place where the research of NS has been done systematically (Taiwan experienced the same as Hong Kong that students were not performing well in the NS test despite they performed better in other international assessment tests). Thus, we could know better about the NS of students in Asia with similar backgrounds and educational systems.

In this study, the Authors developed a number sense three-tier test [NSTTT] to examine the differences of Hong Kong and Taiwan students' performance on number sense. The NSTTT is a test that examines students' knowledge of number sense (contents), reasons, and confidence level. The number sense three-tier test [NSTTT] includes a content-tier (first-tier) which examines content knowledge of number sense; a reason-tier (second-tier) which examines a reason selected for the first-tier response; and the confidence-tier (third-tier) which assesses how confident the students are in their answers to the first two-tiers (Yang, \& Li, 2017). The number sense three-tier test (NSTTT) used in this study was designed by the authors. The NSTTT includes five number sense components and each has 8 questions. The third-tier in the NSTTT used the five-point Likert scale, including very confident, confident, neutral, unconfident, very unconfident, to examine students' confidence after they responded to the first two-tier of the questions. It is used to rate the students' confidence level regarding their answers to the first twotier (Yang, \& Li, 2017).

Ultimately, the Authors believes that assessing students' performance and the misconceptions would provide particularly noteworthy contributions in developing better curricula in the two countries since the fact showed that the reforms of both countries' curricula have emphasized and highlighted the development of number sense. The results of this study clarify the situation of students' performance on number sense in the two countries. Furthermore, no study examines the differences on number sense between Hong Kong and Taiwanese students. This also encouraged the authors to conduct the current study. According to the aforementioned issues, this study sought to address these research questions:

1. Are there any significant differences on the NSTTT between Hong Kong and Taiwan students?

2. Are there any significant differences on the methods used by Hong Kong and Taiwan students?

3. What are the key differences and students' misconceptions on the NSTTT between Hong Kong and Taiwan students? 


\section{LITERATURE REVIEW}

\section{Number Sense Components}

Number sense refers to a person's general understanding of numbers and operations, and the ability to handle numerical problems in the daily life situations via the use of flexible and efficient strategies (e.g. mental computation or proficient estimation) (Markovits \& Sowder, 1994; McIntosh et al., 1992; Reys \& Yang, 1998; Yang, $\& \mathrm{Li}, 2013)$. Number sense components have been broadly discussed by many studies and documents over the past two decades (Berch, 2005; Chen, Li, \& Yang, 2015; Gersten, Jordan, \& Flojo, 2005; Jordan et al., 2010; Markovits, \& Sowder, 1994; McIntosh et al., 1992; NCTM, 2000; Reys, \& Yang, 1998; Verschaffel et al., 2007; Yang, \& Li, 2008). Based on the above references, this study defined that number sense components should include five pivotal components. They are: $\mathrm{C} 1$ : Being able to understand the basic meaning of numbers and operations; $\mathrm{C} 2$ : Being able to recognize the number size; C3: Being able to use multiple representations of numbers and operations; C4: Being able to recognize the relative effect of operations on numbers; and C5: Being able to judge the reasonableness of a computational result via different strategies.

\section{Number Sense Three-tier Test Related Studies}

Due to the importance of number sense, several studies have developed and applied the number sense webbased two-tier test to assess children's number sense performance (e.g., Chen, Li, \& Yang, 2015; Yang, \& Li, 2008). The first-tier test in the two-tier test assesses content knowledge of number sense, and the second-tier test examines children's reasons for their related choice made in the first-tier test (Chen, Li, \& Yang, 2015; Yang, \& Li, 2008). However, this two-tier test does not allow students to rate the strength of their confidence as to why they selected their answers to the first two-tiers (Caleon \& Subramaniam, 2010; Clement, Brown, \& Zietsman, 1989). Based on the three-tier tests used in science education (Caleon, \& Subramaniam, 2010; Cetin-Dindar, \& Geban, 2011; Pesman, \& Eryilmaz, 2010), Yang and Li (2017) designed and applied the number sense three-tier test to measure students' number sense performance, misconceptions, and the level of confidence.

The findings of earlier studies in Science (e.g., Caleon, \& Subramaniam, 2010; Cetin-Dindar, \& Geban, 2011; Pesman, \& Eryilmaz, 2010) showed that the three-tier test can be a more reliable and valid instrument than the twotier tests to identify students' conceptual understanding and the strength of students' confidence level to answer questions can be used to confirm students' misconceptions. The findings of studies by Lin, Yang, and Li (2016) and Yang and Li (2017) showed that many sample students performed poorly on number sense, but with extremely high confidence indicating that many students have significant misconceptions and some students may lack number sense. This study also confirmed that a third-tier (with confidence rating) number sense test can be used to mitigate the weakness of a two-tier test.

\section{Number Sense Related Studies in Hong Kong and Taiwan}

The authors must point out that there are only few studies on number sense involving Hong Kong and Taiwan. Such studies have focused on students' performance on number sense. There is only one published article by Aunio et al. (2004) concerning number sense in Hong Kong. However, number sense has recently received a growing attention from researchers in Taiwan, though there are only few published research works in the literature. Aunio et al. (2004) investigated young children's number sense in Finland, Hong Kong, and Singapore. Their results showed a significant age-related gain in counting and relational skills of number sense, and no gender differences were found. They reported that children in Hong Kong and Singapore outperformed the children in Finland on relational and counting skill tasks, and the students in Singapore performed better than in Hong Kong. On the other hand, the existing studies in the literature have consistently shown that primary school children in Taiwan performed poorly on number sense-related questions in the last two decades (see, e.g., Reys, \& Yang, 1998; Yang, \& Li, 2008, 2017; Yang, \& Wu, 2010).

In the preliminary investigation, Reys and Yang (1998) not only investigated the relationship between number sense and written computation test performance for the sixth and eighth graders in Taiwan but also interviewed the students to examine their responses to number sense-related questions. They found that those students were much more successful on written computation than on number sense. They pointed out that children who are successful in written computation do not necessarily have a well-developed number sense. In addition, Yang (2003) investigated the number sense performance of the fifth graders in Taiwan and found that the students' performance was low with a mean percentage of correct answer about 32\%. Further, Yang and Li (2008) studied the number sense performance of the third-grade students and reported that the students did not perform well on the number sense test with the mean percentage of the correct answer around $34 \%$. 
Afterward, Yang and Wu (2010) conducted a teaching experiment for the third-grade students on number sense through paper-and-pencil tests and interviews. The authors compared the performance of students who received integration of number sense activities in instruction with students who received instruction using regular mathematics textbooks. They found that the students in the experimental class [exposed to number sense-teaching materials (pedagogy)] performed significantly better than in the control class (received regular textbooks instruction) in solving number sense problems and using number sense-based methods to solve the problems. Nevertheless, Yang and Li (2008) argued that the reason of those primary students having low performance on number sense could be related to the contents of mathematics textbooks that do not present number sense-related activities, which influence teachers to not teach number sense in mathematics classes.

\section{Related Studies on Students' Misconceptions}

Reported in the existing literature, the majority of students found considerable misconceptions in solving mathematics problem involving computation and representation, particularly related to fraction, decimal, and multiplication and division. Regarding the computation, majority students performed several misconceptions in fractions (see, e.g., Alghazo, \& Alghazo, 2017; Ashlock, 2006; Education Development Center in USA, 2015; Trivena, Ningsih, \& Jupri, 2017), such as adding both numerators and denominators (e.g., $1 / 3+2 / 5=3 / 8$ ), keeping the same numerator and adding the denominators (e.g., $2 / 3+2 / 5=2 / 8$ ), writing the least denominator and adding the numerators (e.g., $2 / 3+3 / 6=5 / 3$ ), students often fail to convert fractions to a common, equivalent denominator before adding or subtracting them, and instead just use the larger of the two denominators in the answer (e.g., $4 / 3$ $+4 / 6=8 / 6$ ), leaving the denominator unchanged in fraction addition and multiplication problems (e.g., $2 / 5 \times 1 / 5$ $=2 / 5)$.

Regarding the representation, Dhlamini and Kibirige (2014) found that students don't use the representation

properly to represent a fraction or decimal (e.g., the shaded part in

is $1 / 3)$. In addition, Durkin and RittleJohnson (2015) also found that the majority of students are not able to place a number on a number line (e.g., the arrow pointing in the picture $\frac{1}{4} \quad 1 \quad 1$ is 0.6). Griffin (2016) also observed that students perform misconceptions on reading and presenting the value in decimal (e.g., $1 / 2+0.5=1.5 / 2)$. Moreover, regarding the computation, Joseph (2014) argued that the order of operations regarding mnemonic device PEMDAS (Parentheses, Exponents, Multiplication, Division, Addition and Subtraction) influenced heavily on students' misconceptions in solving multiplication and division. Therefore, students tended to solve the multiplication before division (e.g., $125 \div 2 \times 3=125 \div(2 \times 3)$ ). In addition, America's Choice (2012) documented that students may know the commutative property of multiplication but fails to apply it to simplify the work of multiplication (e.g., $100 \div 3 \times 10=100 \div 10 \times 3$ ).

\section{METHOD}

\section{Samples}

125 fifth graders (about 10-11 years old) and 942 sixth graders (about 11-12 years old) from Hong Kong and 819 fifth graders (about 10-11 years old) from Taiwan willingly participated in the number sense three-tier test. The sample included 39 classes from sixth graders and 5 classes from fifth graders of Hong Kong and 31 classes from fifth graders of Taiwan. The elementary educational system (i.e., from grade 1 to grade 6) in Hong Kong and Taiwan is similar. The test was conducted in the two locations by using Chinese version. All of the students in the test are fluent in Chinese. The grade 5 and grade 6 students in Hong Kong were from fourteen elementary schools located in different districts with varied socio-economic status. The grade 5 students in Taiwan were from twelve elementary schools located in different areas (i.e., north, middle, and south area) with varied socio-economic status. The difference of students' socio-economic status in Taiwan is more obvious as compared to students from Hong Kong, because Hong Kong is a big city and Taiwan contains a wider range of areas.

\section{Instrument}

The NSTTT contains the two-tier test and the third-tier (confidence-tier), which assesses how confident the students are, in their answers to the first two-tiers (Yang \& Li, 2017). The two-tier test consists of a content-tier which examines content knowledge of number sense (first-tier); and a reason-tier which examines a reason selected for the first-tier response. The three-tier test consists of the two-tier test and the third-tier (confidence-tier), which assesses how confident the students are, in their answers to the first two-tiers (Yang \& Li, 2017). The number sense three-tier test (NSTTT) used in this study was designed by the authors (Yang \& Li, 2017). The third-tier used the five-point Likert scale, including Very Confident, Confident, Neutral, Unconfident, Very Unconfident, to examine 
Step 1 : Student choose an answer.

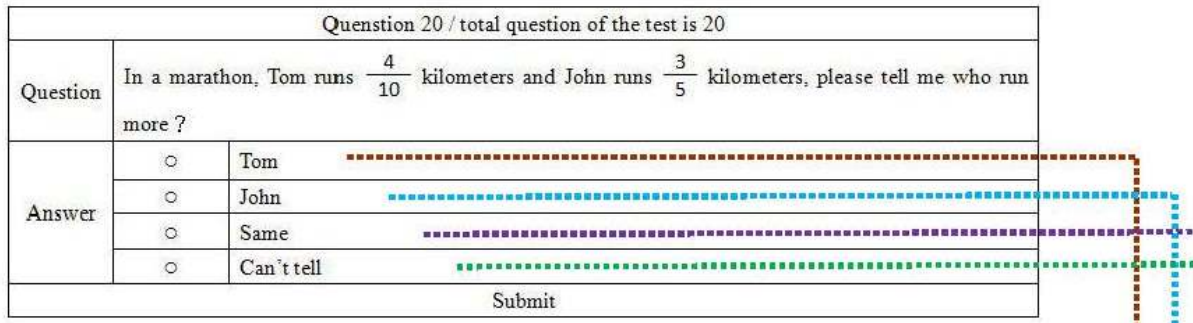

Step 2: According to the answer, the student is required to choose a reason for the selection.

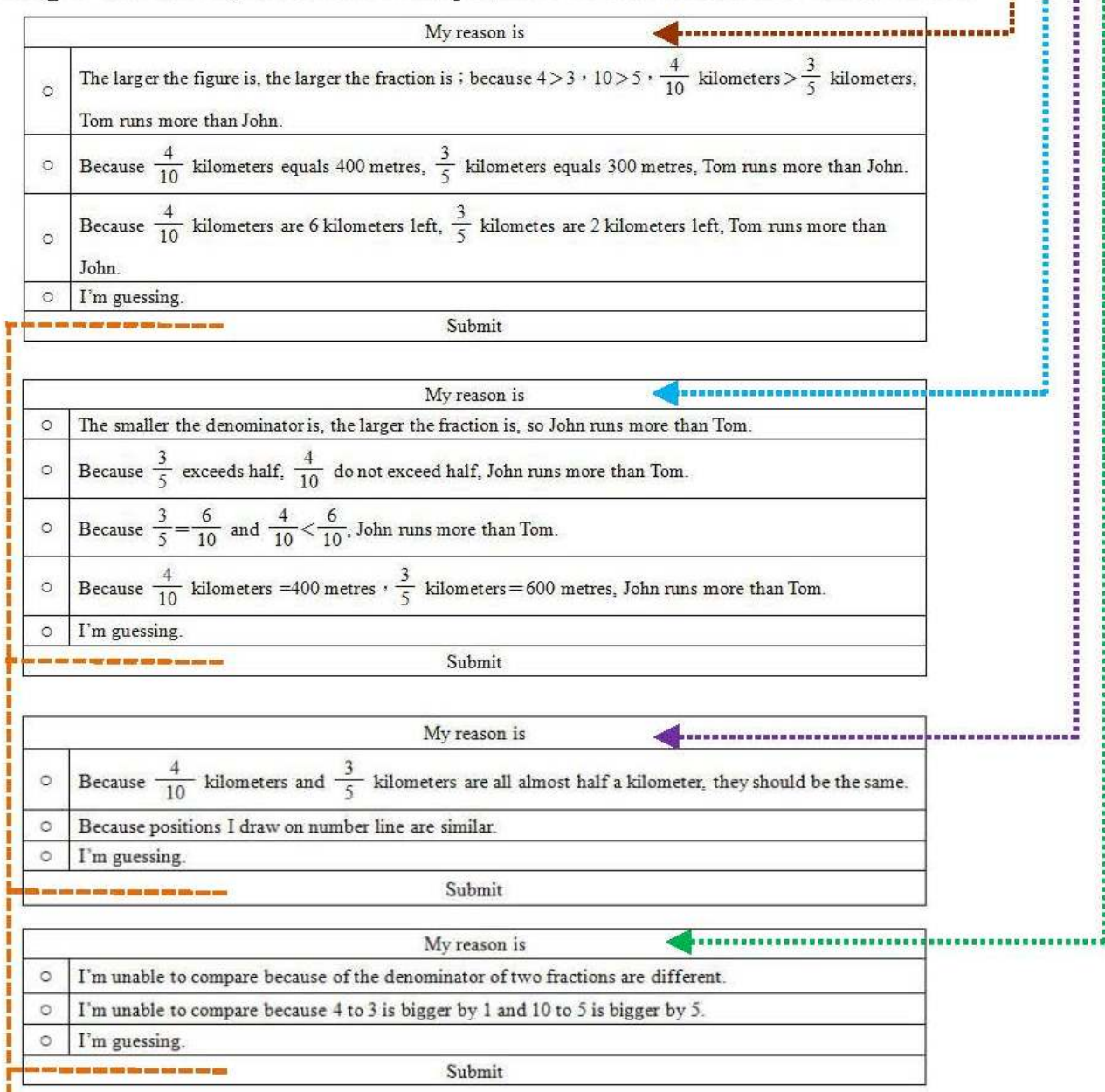

Step 3: According to the reason, the student is required choose a certainy for the selection.

\begin{tabular}{|c|l|}
\hline$\circ$ & Very Confident \\
\hline$\circ$ & Confident \\
\hline$\circ$ & Unconfident \\
\hline$\circ$ & Very Unconfident \\
\hline$\circ$ & General \\
\hline \multicolumn{3}{|c|}{ Submit } \\
\hline
\end{tabular}

Figure 1. An Example of the NSTTT

students' confidence after they responded to the first two-tier of the questions. It is used to rate how confident students are about their answers to the first two-tier (Yang, \& Li, 2017). The NSTTT includes five number sense components as described in the literature reviews and each has 8 items. So, there are 40 items totally. An Example of the NSTTT is described in Figure 1. 
Table 1. The scoring rule of the three-tier test

\begin{tabular}{|c|c|c|c|c|c|c|}
\hline \multirow{3}{*}{ 1st stage } & \multicolumn{6}{|c|}{ Number Sense Test } \\
\hline & \multirow{2}{*}{ Answer options } & \multicolumn{4}{|c|}{ Correct answer } & \multirow{3}{*}{$\begin{array}{c}\text { Wrong answer } \\
0 \\
\end{array}$} \\
\hline & & \multicolumn{4}{|c|}{4 points } & \\
\hline \multirow{3}{*}{ 2nd stage } & \multirow{2}{*}{ Reason options } & NS-based & Rule-Based & Misconception & Guessing & \\
\hline & & 4 & 2 & 1 & 0 & 0 \\
\hline & Score & 8 & 6 & 5 & 4 & 0 \\
\hline & \multicolumn{6}{|c|}{ (CRI in a NS test) } \\
\hline \multirow[t]{2}{*}{ 3rd stage } & CRI & Very confident & Confident & Neutral & Unconfident & Very Unconfident \\
\hline & Score & 5 & 4 & 3 & 2 & 1 \\
\hline
\end{tabular}

\section{Treatment of Data}

Based on the earlier studies of three-tier test by the authors (Caleon, \& Subramaniam, 2010; Cetin-Dindar, \& Geban, 2011; Pesman, \& Eryilmaz, 2010; Yang, \& Li, 2017), the scoring rules were defined in Table 1.

The NSTTT includes the choice of answer and reason, so the scoring rules were described as follows:

1. If the answer was correct, then 4 point was given; if the selection of reason was the number sense-based method, then 4 more point was given; if the selection of reason was the rule-based method, then 2 more points was given; if the selection of reason was a misconception, then 1 more point was given; if the selection of reason was a guess, then 0 points were given.

2. If the answer was incorrect, then 0 more points were given.

Based on the earlier studies, students' significant misconceptions were examined (Caleon, \& Subramaniam, 2010; Tan, Goh, Chia, \& Treagust, 2002; Yang, \& Li, 2017). These significant misconceptions are associated with the incorrect first two-tier options that are selected by at least $10 \%$ of the sample fifth graders (Caleon, \& Subramaniam, 2010; Tan et al., 2002). Students' confidence ratings with their significant misconceptions were computed. In addition, the significant misconceptions were divided into two different categories: genuine misconceptions and spurious misconception, according to the study of Caleon and Subramaniam (2010) in the science education. If the mean confidence ratings associated with the significant misconceptions are above 3 , then the significant misconceptions are defined as genuine misconceptions. If the mean confidence ratings associated with the significant misconceptions are below 3, then the significant misconceptions are defined as spurious misconceptions (Caleon, \& Subramaniam, 2010). This will help us to identify whether sample students have real misconceptions or lack of knowledge which demanding more attention in further remedial instructions and research studies (Yang, \& Li, 2017).

Students' incorrect responses on the both-tier test over $18.3 \%(1 / 12+10 \%)$ were defined as significant misconceptions in the present study (Yang \& Li, 2017). Based on the earlier studies, the mean confidence associated with the significant misconceptions above 2.9 (out of 5) (Caleon, \& Subramaniam, 2010; Yang \& Li, 2017) were defined as genuine misconceptions. Moreover, moderate and strong misconceptions are genuine misconceptions expressed with medium level (between 2.9 and 3.3) and high level (3.3 and above) of mean confidence, respectively (Caleon, \& Subramaniam, 2010; Yang, \& Li, 2017). In addition, the mean confidence ratings associated with the significant misconceptions below 2.9 (out of 5) were defined as spurious misconceptions (Caleon, \& Subramaniam, 2010; Yang, \& Li, 2017). According to the definitions, it helps this study identify whether sample students have real misconceptions or lack of knowledge which demanding more attention in further remedial instruction and research studies.

\section{Procedures}

The data was collected through an on-line test. This test was divided into two parts (Part I and Part II) and each part included 20 questions. Each question includes the answer choice, reason choice, and confidence choice and the time limits are within forty seconds, sixty seconds, and twenty seconds, respectively. Therefore, each question needs 120 seconds and each part needs about 45 minutes to complete the on-line test (Yang, \& Li, 2017).

\section{Reliability and Validity}

The Cronbach's a coefficients of the three-tier test for each number sense component and the whole test are .856 , $.840, .873, .857, .823$, and .902 (Yang, \& Li, 2017). The results of the SEM-based construct reliability of the three-tier test on each component and the whole test are $.827, .836, .840, .828, .839, .905$ (Yang, \& Li, 2017). Authors' study also showed that the three-tier test has good content validity and construct validity. 
Table 2. The results of HK and Taiwan students' performance on number sense three-tier test

\begin{tabular}{|c|c|c|c|c|c|c|c|c|c|c|}
\hline \multirow{3}{*}{ Component } & \multirow{3}{*}{$\begin{array}{l}\text { Number } \\
\text { of Item }\end{array}$} & \multirow{2}{*}{\multicolumn{3}{|c|}{$\begin{array}{c}\text { Mean of both-tiers } \\
\text { (Correct \%) } \\
\end{array}$}} & \multirow{2}{*}{\multicolumn{3}{|c|}{ SD }} & \multirow{2}{*}{\multicolumn{3}{|c|}{$\begin{array}{c}\text { Mean of confidence } \\
\text { (SD) } \\
\end{array}$}} \\
\hline & & & & & & & & & & \\
\hline & & $\frac{\mathrm{HK} 5}{(\mathrm{~N}=125)}$ & $\begin{array}{c}\text { HK6 } \\
(\mathrm{N}=942)\end{array}$ & $\begin{array}{c}\text { TW5 } \\
(\mathrm{N}=819)\end{array}$ & HK5 & HK6 & TW5 & HK5 & HK6 & TW5 \\
\hline \multirow{2}{*}{ C1 } & \multirow{2}{*}{8} & 36.18 & 35.89 & 27.90 & \multirow{2}{*}{13.00} & \multirow{2}{*}{14.27} & \multirow{2}{*}{15.48} & 4.50 & 4.30 & 4.07 \\
\hline & & (56.53\%) & (56.08\%) & (43.60\%) & & & & -1.03 & -1.14 & -1.2 \\
\hline \multirow{2}{*}{ C2 } & \multirow{2}{*}{8} & \multirow{2}{*}{$\begin{array}{c}41.38 \\
(64.66 \%)\end{array}$} & \multirow{2}{*}{$\begin{array}{c}39.80 \\
(62.19 \%)\end{array}$} & \multirow{2}{*}{$\begin{array}{c}35.32 \\
(55.19 \%)\end{array}$} & \multirow{2}{*}{14.14} & \multirow{2}{*}{12.05} & \multirow{2}{*}{12.03} & 4.63 & 4.41 & 4.22 \\
\hline & & & & & & & & -0.89 & -1.07 & -1.15 \\
\hline \multirow{2}{*}{ C3 } & \multirow{2}{*}{8} & \multirow{2}{*}{$\begin{array}{c}37.83 \\
(59.11 \%) \\
\end{array}$} & \multirow{2}{*}{$\begin{array}{c}36.92 \\
(57.69 \%) \\
\end{array}$} & \multirow{2}{*}{$\begin{array}{c}28.43 \\
(44.2 \%) \\
\end{array}$} & \multirow{2}{*}{13.98} & \multirow{2}{*}{15.50} & \multirow{2}{*}{15.70} & 4.41 & 4.22 & 4.01 \\
\hline & & & & & & & & -1.11 & -1.9 & -1.23 \\
\hline \multirow{2}{*}{ C4 } & \multirow{2}{*}{8} & \multirow{2}{*}{$\begin{array}{c}36.46 \\
(56.98 \%) \\
\end{array}$} & \multirow{2}{*}{$\begin{array}{c}32.51 \\
(50.79 \%)\end{array}$} & \multirow{2}{*}{$\begin{array}{c}26.54 \\
(41.46 \%)\end{array}$} & \multirow{2}{*}{14.01} & \multirow{2}{*}{12.40} & \multirow{2}{*}{12.75} & 4.49 & 4.27 & 4.13 \\
\hline & & & & & & & & -1.07 & -1.17 & -1.18 \\
\hline \multirow{2}{*}{$\mathrm{C} 5$} & \multirow{2}{*}{8} & 27.71 & 27.56 & 26.85 & & & & 4.39 & 4.17 & 4.13 \\
\hline & & (43.30\%) & (43.06\%) & (41.95\%) & 12.61 & 12.33 & 12.53 & -1.13 & -1.22 & -1.17 \\
\hline Total & & 179.57 & 172.68 & 145.04 & 5736 & 5534 & 5640 & 4.47 & 4.27 & 4.12 \\
\hline Scores & & (56.12\%) & (53.96\%) & (45.32\%) & 31.36 & 53.34 & 56.40 & -1.05 & -1.16 & -1.19 \\
\hline
\end{tabular}

Note. C1: Being able to understand the basic meaning of numbers and operations; C2: Being able to recognize the number size; C3: Being able to use multiple representations of numbers and operations; C4: Being able to recognize the relative effect of operations on numbers; $\mathrm{C} 5$ : Being able to judge the reasonableness of a computational result via different strategies.

Table 3. The results of ANOVA test among students' performance on both-tiers and confidence, and the results of post hoc test of Scheffe among HK5, HK6, and TW5

\begin{tabular}{|c|c|c|c|c|c|c|c|}
\hline & $\begin{array}{l}\text { Sum of } \\
\text { Squares }\end{array}$ & Df & Mean Square & $\mathbf{F}$ & Sig. & & \\
\hline Between Groups & 61.07 & 2 & 30.54 & 62.45 & 0 & & \\
\hline Within Groups & 920.70 & 1883 & 0.49 & & & & \\
\hline \multirow[t]{3}{*}{ Total } & 981.77 & 1885 & & & & & \\
\hline & \multirow{2}{*}{ (I) Group } & \multirow{2}{*}{ (J) Group } & \multirow{2}{*}{$\begin{array}{c}\text { Mean Difference } \\
(I-J)\end{array}$} & \multirow{2}{*}{ Std. Error } & \multirow{2}{*}{ Sig. } & \multicolumn{2}{|c|}{ 95\% Confidence Interval } \\
\hline & & & & & & Lower Bound & Upper Bound \\
\hline \multirow{6}{*}{ Scheffe } & \multirow{2}{*}{ HK6 } & HK5 & -0.100373 & 0.066564 & 0.321 & -0.26343 & 0.06269 \\
\hline & & TW5 & $.347975^{*}$ & 0.033408 & 0 & 0.26614 & 0.42981 \\
\hline & \multirow{2}{*}{ HK5 } & HK6 & 0.100373 & 0.066564 & 0.321 & -0.06269 & 0.26343 \\
\hline & & TW5 & $.448348^{*}$ & 0.067147 & 0 & 0.28386 & 0.61284 \\
\hline & \multirow{2}{*}{ TW5 } & HK6 & $-.347975^{*}$ & 0.033408 & 0 & -0.42981 & -0.26614 \\
\hline & & $\mathrm{HK} 5$ & $-.448348^{*}$ & 0.067147 & 0 & -0.61284 & -0.28386 \\
\hline
\end{tabular}

\section{RESULTS}

\section{The Differences on the NSTTT between Hong Kong and Taiwan Students}

Table 2 reports the results of HK and Taiwan students' performance on number sense 3-tier test. Data show that HK $5^{\text {th }}$ grade students performed the best on the mean scores for each number sense component and whole test. Taiwan $5^{\text {th }}$ grade students performed poorly on the mean scores for each number sense component and whole test. At the same time, $\mathrm{HK} 5^{\text {th }}$ graders have the highest confidence among the three groups when responding to number sense related questions. In order to examine whether the significant differences exist among the three groups on NS both-tiers test and confidence, the ANOVA was conducted.

Table 3 presents the results of ANOVA among students' performance on number sense both-tiers test and mean of confidence, and the results of post hoc test of Scheffe. Data show that there is a significant difference among the sample students $(\alpha=.05)$. Therefore, the post hoc test of Scheffe was done (see Table 3$)$. Results show that there is a significant difference between $\mathrm{HK} 5^{\text {th }}$ graders and Taiwan $5^{\text {th }}$ graders, and HK $6^{\text {th }}$ graders and Taiwan $5^{\text {th }}$ graders at $a=.05$ level on the mean of both-tiers test and confidence index. This indicates that HK $5^{\text {th }}$ and $6^{\text {th }}$ grade students are not only significantly performed better on NS both-tiers test than Taiwan $5^{\text {th }}$ grade students, but also are more confident in answering NS two-tiers test than Taiwan $5^{\text {th }}$ grade students. 
Table 4. The differences on the methods used by sample students

\begin{tabular}{|c|c|c|c|c|c|c|}
\hline \multirow{3}{*}{ Grade } & \multicolumn{4}{|c|}{ Correct } & \multirow{3}{*}{ Incorrect (\%) } & \multirow{3}{*}{ Confidence } \\
\hline & \multicolumn{4}{|c|}{ Reason (\%) } & & \\
\hline & NS-based & R-based & Misconceptions & Guessing & & \\
\hline $\mathrm{HK}-5^{\text {th }}$ & $33.50 \%$ & $17.36 \%$ & $12.20 \%$ & $4.64 \%$ & $32.30 \%$ & 4.65 \\
\hline $\mathrm{HK}-6^{\text {th }}$ & $33.34 \%$ & $15.08 \%$ & $11.57 \%$ & $3.92 \%$ & $36.09 \%$ & 4.47 \\
\hline Taiwan-5 $5^{\text {th }}$ & $25.57 \%$ & $16.37 \%$ & $10.16 \%$ & $2.37 \%$ & $45.53 \%$ & 4.28 \\
\hline
\end{tabular}

Table 5. The key differences on the number sense performance between HK and Taiwan students

\begin{tabular}{cccccc}
\hline \multirow{2}{*}{ Category } & \multicolumn{3}{c}{ Number Sense Performance } & \multicolumn{2}{c}{ Difference } \\
\cline { 2 - 6 } & HK6 & HK5 & TW5 & HK5 - TW5 & HK6 - TW5 \\
\hline C1-1 & $62 \%$ & $62 \%$ & $41 \%$ & $21 \%$ & $22 \%$ \\
\hline C1-2 & $77 \%$ & $74 \%$ & $54 \%$ & $23 \%$ & $15 \%$ \\
\hline C1-7 & $65 \%$ & $73 \%$ & $50 \%$ & $23 \%$ & $21 \%$ \\
\hline C3-3 & $78 \%$ & $78 \%$ & $57 \%$ & $24 \%$ & $15 \%$ \\
\hline C3-4 & $50 \%$ & $59 \%$ & $36 \%$ & $\mathbf{2 5} \%$ \\
\hline C3-5 & $77 \%$ & $84 \%$ & $53 \%$ & $\mathbf{3 2} \%$ & $19 \%$ \\
\hline C3-8 & $59 \%$ & $69 \%$ & $26 \%$ & $22 \%$ & $22 \%$ \\
\hline C4-2 & $71 \%$ & $74 \%$ & $51 \%$ & $26 \%$ & $15 \%$ \\
\hline C4-3 & $73 \%$ & $77 \%$ & $51 \%$ & $30 \%$ & $22 \%$ \\
\hline C5-3 & $38 \%$ & $53 \%$ & $23 \%$ & $30 \%$ & \\
\hline
\end{tabular}

Note. (1). The number in each cell number sense performance means the correct percentage on the first-tier test;

(2). HK5-TW5 means the difference on the on the correct percentages of number sense first-tier test between HK5 and TW5; (3). The bolded C3-5 and C3-4 as the top two items which showed the key differences on the number sense first-tier test between HK5 and TW5.

\section{The Differences on the Methods Used by Hong Kong and Taiwan Students}

Table 4 reports the results of the differences on the methods used by sample students. Data show that all of the sample students have the low percentage on the use of number sense-based method to solve number sense related questions. Only one-thirds of students could use number sense-based method to solve questions by HK $5^{\text {th }}$ and $6^{\text {th }}$ graders. However, only about one-fourths of students could use number sense-based method to solve questions by Taiwan $5^{\text {th }}$ graders.

In addition, the results of chi-square test $\left(\mathrm{df}=2, x^{2}=268.23, \mathrm{p}<0.0001\right)$ show that there is a significant difference in the incorrect percentages among the three groups (HK $5^{\text {th }}, \mathrm{HK} 6^{\text {th }}$, and Taiwan $5^{\text {th }}$ ). The post hoc test of Scheffe revealed that there is a significant difference in the incorrect responses between HK5 and TW5, and HK6 and TW5. This indicates that Taiwan fifth grade students performed poor on number sense than Hong Kong fifth and sixth grade students. Moreover, the chi-square test $\left(\mathrm{df}=2, x^{2}=199.69, \mathrm{p}<0.0001\right)$ also showed that there is a significant difference in the use of NS-based method among the three groups (HK5, HK6, and TW5).

The results of post hoc tests of Scheffe further show that there is a significant difference in the use of NS-based method between HK5 and TW5, and HK6 and TW5. This indicates that Hong Kong fifth and sixth grade students are better on the use of number sense-based method when responding to number sense related questions.

\section{The Key Differences on the Number Sense Performance between HK and Taiwan Students}

Table 5 reports some items which have key differences on the correct percentages of number sense first-tier test between HK5 (Hong Kong $5^{\text {th }}$ graders) and TW5 (Taiwan $5^{\text {th }}$ graders), and HK6 (Hong Kong $6^{\text {th }}$ graders) and TW5. Data revealed that there are 10 items over $20 \%$ differences on the correct percentages of number sense first-tier test between HK5 and TW5. It implies that there are 10 items HK5 students are $20 \%$ higher than the TW5 students. There are 7 items over $20 \%$ differences on the correct percentages of number sense first-tier test between HK6 and TW5. It means that there are 7 items HK6 students are $20 \%$ higher than the TW5 students. Moreover, there are three items that HK5 students are over $30 \%$ higher on the correct percentages of number sense first-tier test than the TW5 students. In addition, C3-5 and C3-4 are commonly ranked the top two items which have key differences on the number sense first-tier test. Furthermore, to deeply understand the key differences on the three items that HK5 students are $30 \%$ higher on the correct percentages of number sense first-tier test than the TW5 students, we presented the detailed responses results on item C3-5, C3-4, and C4-3 for HK5, HK6, and TW5. 
Table 6. HK5, HK6, and TW5 students' responses to item C3-5

\begin{tabular}{|c|c|c|c|c|c|c|}
\hline & Choices ( & & & $\%$ & Reasons for Choosing Your Answer & Method \\
\hline \multirow{9}{*}{ Denny } & \multirow{3}{*}{ HK6 } & \multirow{3}{*}{$17.80 \%$} & HK6 & $13.20 \%$ & \multirow{3}{*}{ There are four shaded parts } & \multirow{3}{*}{ Misconception } \\
\hline & & & HK5 & $10.40 \%$ & & \\
\hline & & & TW5 & $23.70 \%$ & & \\
\hline & \multirow{3}{*}{ HK5 } & \multirow{3}{*}{$13.60 \%$} & HK6 & $2.40 \%$ & \multirow{3}{*}{$\begin{array}{l}\text { The arrow pointing in the picture of the } \\
\text { number line is } 0.8 \text {, Tom is wrong. }\end{array}$} & \multirow{3}{*}{ Misconception } \\
\hline & & & HK5 & $2.40 \%$ & & \\
\hline & & & TW5 & $3.20 \%$ & & \\
\hline & \multirow{3}{*}{ TW5 } & \multirow{3}{*}{$28.60 \%$} & HK6 & $2.20 \%$ & \multirow{3}{*}{ I'm guessing. } & \multirow{3}{*}{ Guessing } \\
\hline & & & HK5 & $0.80 \%$ & & \\
\hline & & & TW5 & $1.70 \%$ & & \\
\hline \multirow{9}{*}{ Tom } & \multirow{3}{*}{ HK6 } & \multirow{3}{*}{$13.90 \%$} & HK6 & $8.50 \%$ & \multirow{3}{*}{ Counting four to the right from 0 is 0.4 . } & \multirow{3}{*}{ Misconception } \\
\hline & & & HK5 & $5.60 \%$ & & \\
\hline & & & TW5 & $19.40 \%$ & & \\
\hline & \multirow{3}{*}{ HK5 } & \multirow{3}{*}{$8.00 \%$} & HK6 & $4.00 \%$ & \multirow{3}{*}{ Shaded part is $\frac{4}{8}=0.5$, Denny is wrong. } & \multirow{3}{*}{ Misconception } \\
\hline & & & HK5 & $2.40 \%$ & & \\
\hline & & & TW5 & $8.70 \%$ & & \\
\hline & \multirow{3}{*}{ TW5 } & \multirow{3}{*}{$29.80 \%$} & HK6 & $1.40 \%$ & \multirow{3}{*}{ I'm guessing. } & \multirow{3}{*}{ Guessing } \\
\hline & & & HK5 & $0.00 \%$ & & \\
\hline & & & TW5 & $1.70 \%$ & & \\
\hline \multirow{6}{*}{$\begin{array}{l}\text { Both are } \\
\text { correct }\end{array}$} & & & HK6 & $6.60 \%$ & There are four parts are shaded, which means & \\
\hline & HK6 & $9.00 \%$ & HK5 & $9.60 \%$ & 0.4 and counting four to the right from 0 is & Misconception \\
\hline & & & TW5 & $14.70 \%$ & 0.4 & \\
\hline & HKS & $9.60 \%$ & HK6 & $2.40 \%$ & & \\
\hline & TWMI5 & 15400 & HK5 & $0.00 \%$ & I'm guessing. & Guessing \\
\hline & TVV & $15.40 \%$ & TW5 & $0.70 \%$ & & \\
\hline & & & HK6 & $31.90 \%$ & & \\
\hline & & & HK5 & $38.40 \%$ & aded part is $-8=0.5$ and the arrow pointing & Misconception \\
\hline & HK6 & $59.20 \%$ & TW5 & $12.30 \%$ & in the picture of the number line is 0.8 . & \\
\hline & & & HK6 & $1.90 \%$ & & \\
\hline & & & HK5 & $2.40 \%$ & 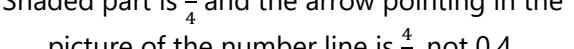 & Misconception \\
\hline *Both are & HK5 & $6880 \%$ & TW5 & $1.60 \%$ & picture of the number line is $\frac{-}{6}{ }^{\prime}$ not 0.4 & \\
\hline false & HRJ & $00.00 \%$ & HK6 & $20.10 \%$ & & \\
\hline & & & HK5 & $17.60 \%$ & nicture of the number line is 4 net 04 & NS-based \\
\hline & & & TW5 & $10.10 \%$ & picture of the number line is $\frac{1}{6}$, not 0.4 & \\
\hline & TW/5 & $2630 \%$ & HK6 & $5.30 \%$ & & \\
\hline & TVVS & $20.30 \%$ & HK5 & $10.40 \%$ & I'm guessing. & Guessing \\
\hline & & & TW5 & $2.20 \%$ & & \\
\hline
\end{tabular}

Note. * indicates the correct answer.

\section{C3-5: Consider the decimal 0.4, which one's statement is true?}

\section{Denny: If the whole cycle is 1 , then the shaded part is 0.4 .}

Tom: The arrow pointing in the picture of the number line

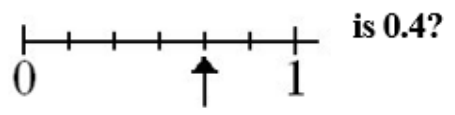

C3-5 is used to examine whether students are being able to use multiple representations of numbers and its operations or not. Table 6 reports the results of HK5, HK6, and TW6 students' responses to item C3-5. Data show that the correct percentages of HK5 and HK6 are over $42.5 \%$ and $32.9 \%$ on this item than TW5 students. Results show that there are $28.6 \%$ of TW5 students believed that Denny's statement is correct. The percentage is much higher than the selection of HK5 (13.6\%) and HK6 (17.8\%). In further examining the selection of reason choice ( $2^{\text {nd }}$ tier test), we can see that $23.7 \%$ of TW5 students selected "There are four shaded parts." This is much higher than the choice of HK5 (10.4\%) and HK6 (13.2\%). In addition, there are $29.8 \%$ of TW5 students believed that Tom's statement is correct. This is much more serious and much higher than the selection of HK5 (8.0\%) and HK6 (13.9\%). In further investigating the selection of reason choice, we can see that $19.7 \%$ of TW5 students selected "Counting four to the right from 0 is 0.4 ." This is much higher than the choice of HK5 (5.6\%) and HK6 (8.5\%). Moreover, $14.6 \%$ of TW5 students believed that both statements are correct and on the reason choice they selected the "There are four parts are shaded, which means 0.4 and counting four to the right from 0 is 0.4 ." The percentage is also much 
Table 7. HK5, HK6, and TW5 students' responses to item C3-4

\begin{tabular}{|c|c|c|c|c|c|c|}
\hline & $\operatorname{ces}(\%)$ & & & $\%$ & Reasons for Choosing Your Answer & Method \\
\hline \multirow{9}{*}{$3 \frac{4}{12}$ meters } & \multirow{3}{*}{ HK6 } & \multirow{3}{*}{$12.40 \%$} & HK6 & $8.60 \%$ & \multirow{3}{*}{$\begin{array}{l}\text { There are three } 1 \text { meter, and } \frac{1}{2}+\frac{1}{4}+\frac{1}{2}+\frac{1}{4}= \\
\frac{4}{12^{\prime}} \text {, so the answer is } 3 \frac{4}{12} \text { meters. }\end{array}$} & \multirow{3}{*}{ Misconception } \\
\hline & & & HK5 & $6.40 \%$ & & \\
\hline & & & TW5 & $26.10 \%$ & & \\
\hline & \multirow{3}{*}{ HK5 } & \multirow{3}{*}{$8.80 \%$} & HK6 & $1.20 \%$ & \multirow{3}{*}{$\begin{array}{l}\text { There are only three } 1 \text { meter, so it couldn't } \\
\text { over } 4 \text { meters. }\end{array}$} & \multirow{3}{*}{ Misconception } \\
\hline & & & HK5 & $0.80 \%$ & & \\
\hline & & & TW5 & $2.00 \%$ & & \\
\hline & \multirow{3}{*}{ TW5 } & \multirow{3}{*}{$32.00 \%$} & HK6 & $2.70 \%$ & \multirow{3}{*}{ I'm guessing. } & \multirow{3}{*}{ Rule-based } \\
\hline & & & HK5 & $1.60 \%$ & & \\
\hline & & & TW5 & $3.90 \%$ & & \\
\hline \multirow{9}{*}{ * $4 \frac{2}{4}$ meters } & \multirow{3}{*}{ HK6 } & \multirow{3}{*}{$77.40 \%$} & HK6 & $60.30 \%$ & \multirow{3}{*}{$\begin{array}{l}\text { There are three } 1 \text { meter, two } \frac{1}{2} \text { meter, and } \\
\text { two } \frac{1}{4^{\prime}} \text { adding them up, then I got } 4 \frac{2}{4} \\
\text { meters. }\end{array}$} & \multirow{3}{*}{ NS-based } \\
\hline & & & HK5 & $57.60 \%$ & & \\
\hline & & & TW5 & $39.30 \%$ & & \\
\hline & \multirow{3}{*}{ HK5 } & \multirow{3}{*}{$84.00 \%$} & HK6 & $12.90 \%$ & \multirow{3}{*}{$\begin{array}{c}\frac{1}{2}+1+\frac{1}{4}+1+\frac{1}{2}+1+\frac{1}{4}=4 \frac{2}{4}, \text { so the } \\
\text { answer is } 4 \frac{2}{4} \text { meters. }\end{array}$} & \multirow{3}{*}{ Rule-based } \\
\hline & & & HK5 & $20.00 \%$ & & \\
\hline & & & TW5 & $10.10 \%$ & & \\
\hline & \multirow{3}{*}{ TW5 } & \multirow{3}{*}{$52.50 \%$} & HK6 & $4.30 \%$ & \multirow{3}{*}{ I'm guessing. } & \multirow{3}{*}{ Guessing } \\
\hline & & & HK5 & $6.40 \%$ & & \\
\hline & & & TW5 & $3.10 \%$ & & \\
\hline \multirow{6}{*}{5 meters } & \multirow{2}{*}{ HK6 } & \multirow{2}{*}{$7.90 \%$} & HK6 & $6.50 \%$ & \multirow{3}{*}{$\begin{array}{l}\text { There are three } 1 \text { meter, adding the others } \\
\text { up is } 2 \text { meters, so the answer is } 5 \text { meters. }\end{array}$} & \\
\hline & & & HK5 & $4.80 \%$ & & Misconception \\
\hline & HK5 & $560 \%$ & TW5 & $8.20 \%$ & & \\
\hline & HK5 & $5.60 \%$ & HK6 & $1.40 \%$ & & \\
\hline & TWM & $1000 \%$ & HK5 & $0.80 \%$ & I'm guessing. & Guessing \\
\hline & IWS & $10.00 \%$ & TW5 & $1.80 \%$ & & \\
\hline & HKG & $230 \%$ & HK6 & $1.60 \%$ & & \\
\hline & HKG & $2.30 \%$ & HK5 & $1.60 \%$ & $\begin{array}{l}\text { There are } / \text { symbols, so the answer is } 7 \\
\text { meters }\end{array}$ & Misconception \\
\hline 7 meters & HK5 & $160 \%$ & TW5 & $3.10 \%$ & & \\
\hline 1 meters & HKS & $1.60 \%$ & HK6 & $0.70 \%$ & & \\
\hline & TWW15 & $550 \%$ & HK5 & $0.00 \%$ & I'm guessing. & Guessing \\
\hline & IVVS & $5.50 \%$ & TW5 & $2.40 \%$ & & \\
\hline
\end{tabular}

higher than HK5 (9.6\%) and HK6 (6.6\%). The findings show that Taiwan fifth grade students have serious misconceptions on the meaning of fractions and decimals, their relationship between fractions and decimals, and the use of multiple representations of fractions and decimals.

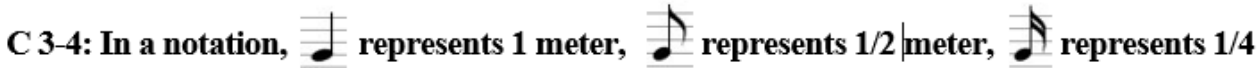

meter.

\section{What is the total meter of the notation below?}

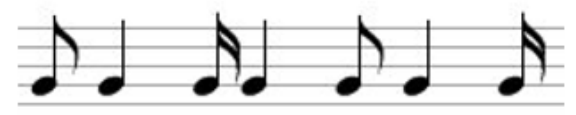

C3-4 is also used to examine whether students are being able to use multiple representations of numbers and operations or not. Table 7 shows the results of HK5, HK6, and TW6 students' responses to item C3-4. Data show that the correct percentages of HK5 and HK6 are over 31.5\% and $24.9 \%$ higher on this item than TW5 students. Results also show that there are $32.0 \%$ of TW5 students believed that the answer is $3 \frac{4}{12}$ meters. The percentage is much higher than the selection of HK5 (8.8\%) and HK6 (12.4\%). In further examining the selection of reason choice

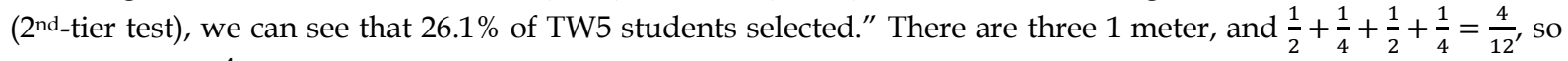
the answer is $3 \frac{4}{12}$ meters.." This is much higher than the choice of HK5 (6.4\%) and HK6 (8.6\%). This finding showed that Taiwan fifth grade students have serious misconception on the addition of fractions with different denominators than Hong Kong fifth and sixth grade students. Over one-fourths of Taiwan fifth grade students believed that $\frac{1}{2}+\frac{1}{4}+\frac{1}{2}+\frac{1}{4}=\frac{4}{12}$. It is obvious that these students tried to apply the rule of the addition of whole numbers to the addition of fractions and without meaningful thinking the meanings of fractions. 
Table 8. HK5, HK6, and TW5 students' responses to item C4-3

\begin{tabular}{|c|c|c|c|c|c|c|}
\hline \multicolumn{3}{|c|}{ Choices (\%) } & \multicolumn{2}{|r|}{$\%$} & Reasons for Choosing your Answer & \multirow[t]{2}{*}{ Method } \\
\hline \multirow{9}{*}{ Student A } & \multirow{3}{*}{ HK6 } & \multirow{3}{*}{$34.30 \%$} & HK6 & $20.10 \%$ & \multirow{3}{*}{$\begin{array}{l}\text { Multiplication/division takes precedence over } \\
\text { addition/subtraction, so multiplication }(5 \times 6) \\
\text { should be done prior to division. }\end{array}$} & \\
\hline & & & HK5 & $12.80 \%$ & & \multirow[t]{2}{*}{ Misconception } \\
\hline & & & TW5 & $37.10 \%$ & & \\
\hline & \multirow{3}{*}{ HK5 } & \multirow{3}{*}{$21.60 \%$} & HK6 & $7.60 \%$ & \multirow{3}{*}{$\begin{array}{l}\text { The bracket makes no difference to the } \\
\text { operations. So student A's solution is the } \\
\text { same as the problem. }\end{array}$} & \multirow{3}{*}{ Misconception } \\
\hline & & & HK5 & $4.80 \%$ & & \\
\hline & & & TW5 & $7.20 \%$ & & \\
\hline & \multirow{3}{*}{ TW5 } & \multirow{3}{*}{$48.70 \%$} & $\mathrm{HH} 6$ & $6.60 \%$ & \multirow{3}{*}{ I'm guessing. } & \multirow{3}{*}{ Guessing } \\
\hline & & & HK5 & $4.00 \%$ & & \\
\hline & & & TW5 & $4.40 \%$ & & \\
\hline \multirow{9}{*}{ * Student B } & \multirow{3}{*}{ HK6 } & \multirow{3}{*}{$38.00 \%$} & HK6 & $24.40 \%$ & \multirow{3}{*}{$\begin{array}{l}\text { Multiplication/division takes precedence over } \\
\text { addition/subtraction, so multiplication } \\
(1234 \times 6) \text { first and division later is the same as } \\
\text { reversing the order. }\end{array}$} & \multirow{3}{*}{ NS-based } \\
\hline & & & HK5 & $42.40 \%$ & & \\
\hline & & & TW5 & $14.90 \%$ & & \\
\hline & \multirow{3}{*}{ HK5 } & \multirow{3}{*}{$52.80 \%$} & HK6 & $7.90 \%$ & \multirow{3}{*}{ 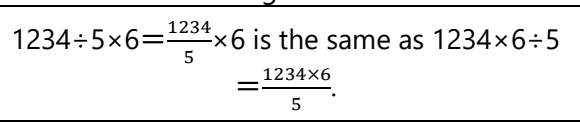 } & \multirow{3}{*}{ Rule-based } \\
\hline & & & HK5 & $7.20 \%$ & & \\
\hline & & & TW5 & $3.80 \%$ & & \\
\hline & \multirow{3}{*}{ TW5 } & & HK6 & $5.70 \%$ & & \\
\hline & & $22.83 \%$ & HK5 & $3.20 \%$ & I'm guessing. & Guessing \\
\hline & & & TW5 & $4.20 \%$ & & \\
\hline & & & HK6 & $12.20 \%$ & The order of the numbers in multiplication & \\
\hline & HK6 & $20.91 \%$ & HK5 & $11.20 \%$ & problems does not matter, so $5 \times 6$ can be & Misconception \\
\hline & & & TW5 & $12.30 \%$ & replaced by $6 \times 5$ & \\
\hline & & & HK6 & $4.10 \%$ & & \\
\hline Student C & HK5 & $21.60 \%$ & HK5 & $7.20 \%$ & $\begin{array}{c}\div 5 \times 6 \text { and } \div 6 \times 5 \text { are the same, } 1234 \div 5 \times 6= \\
1234 \div 6 \times 5\end{array}$ & Misconception \\
\hline & & & TW5 & $4.90 \%$ & & \\
\hline & & & HK6 & $4.60 \%$ & & \\
\hline & TW5 & $20.27 \%$ & HK5 & $3.20 \%$ & I'm guessing. & Guessing \\
\hline & & & TW5 & $3.60 \%$ & & \\
\hline & & & HK6 & $2.80 \%$ & Multiplication/division takes precedence over & \\
\hline & HK6 & $6.79 \%$ & HK5 & $2.40 \%$ & addition/subtraction, so multiplication $(5 \times 6)$ & Misconception \\
\hline & & & TW5 & $4.90 \%$ & should be worked on prior to division. & \\
\hline & & & HK6 & $1.90 \%$ & The order of the numbers in division does not & \\
\hline Student D & HK5 & $4.00 \%$ & HK5 & $0.00 \%$ & matter, so the answer will remain the same if & Misconception \\
\hline & & & TW5 & $2.20 \%$ & $5 \times 6$ is placed before 1234 & \\
\hline & & & HK6 & $2.10 \%$ & & \\
\hline & TW5 & $8.18 \%$ & HK5 & $1.60 \%$ & I'm guessing. & Guessing \\
\hline & & & TW5 & $1.10 \%$ & & \\
\hline
\end{tabular}

\section{C4-3: Four students tried to solve this problem: $1234 \div 5 \times 6$. Whose solution is correct?}

Student A: $1234 \div 5 \times 6=1234 \div(5 \times 6)$; Student B: $1234 \div 5 \times 6=1234 \times 6 \div 5$; Student C: $1234 \div 5 \times 6=1234 \div 6 \times 5$; Student D: $1234 \div 5 \times 6=5 \times 6 \div 1234$

C4-3 is used to examine whether students are Being able to recognize the relative effect of operations on numbers or not. Table 8 shows the results of HK5, HK6, and TW6 students' responses to item C4-3. Data show that the correct percentages of HK5 and HK6 are 30.0\% and 15.2\% higher on item C4-3 than TW5 students. All of the sample students have higher misconceptions on this item, especially the Taiwan fifth grade students. In addition, several different misconceptions were found. For example, there are $48.7 \%$ of TW5 students believed that "Student A: $1234 \div 5 \times 6=1234 \div(5 \times 6)$ " is correct which is much higher than the selection of HK5 $(21.6 \%)$ and HK6 (34.3\%). In further examining the selection of reason choice, we can see that $37.1 \%$ of TW5 students selected "Multiplication/division takes precedence over addition/subtraction, so multiplication $(5 \times 6)$ should be done prior to division." This is much higher than the choice of HK5 (12.6\%) and HK6 (20.1\%). Moreover, 7.2\% of TW5, 4.8\% of HK5, and 7.6\% of HK6 students selected "The bracket makes no difference to the operations. So student A's solution is the same as the problem." In addition, about one-fifths of TW5, HK5, and HK6 students believed that "Student C: $1234 \div 5 \times 6=1234 \div 6 \times 5$." In the reason choice, most of them selected: "The order of the numbers in multiplication problems does not matter, so $5 \times 6$ can be replaced by $6 \times 5$." or " $\div 5 \times 6$ and $\div 6 \times 5$ are the same, $1234 \div 5 \times 6=1234 \div 6 \times 5$." It seems reasonable to believe that samples students have serious misconceptions, especially Taiwan fifth grade students, which related to the effect of order of multiplication, division, and parenthesis to the final result. 


\section{The Differences of Students' Misconceptions between Hong Kong and Taiwan Students}

Based on the three-tier test related studies (Caleon, \& Subramaniam, 2010; Tan et al., 2002; Yang, \& Li, 2017), incorrect response rates for the first and second tier that exceeded $18.3 \%$ were defined as significant misconceptions. At the same time, mean confidence scores higher than 3.3 (out of 5) that were associated with significant misconceptions were defined as strong misconceptions (Caleon, \& Subramaniam, 2010; Tan et al., 2002; Yang, \& Li, 2017). Data revealed Hong Kong sixth graders had strong misconceptions for 17 out of 40 items, the Hong Kong fifth graders had strong misconceptions for 18 out of 40 items, and Taiwan fifth grade students had strong misconceptions for 25 out of 40 items. It seems reasonable to believe that students from different subgroups all have serious misconceptions when responding number sense related questions. Especially, TW5 students had over a half of questions belonging to strong misconceptions which is obviously higher than the HK5 and HK6 students who had less than a half of questions belonging to strong misconceptions.

\section{DISCUSSION AND CONCLUSION}

The importance of teaching, learning, and assessment on number sense has been a line of scholarly inquiry for nearly three decades (e.g. Jones et al., 1996; Markovits, \& Sowder, 1994; McIntosh et al., 1992, 1997; NCTM, 1989; Resnick, 1989; Reys, 1994; Sowder, 1992a). On the other hand, studies of students' performance on number sense provided new understanding about relationships between number sense and standard written computation, number sense and mathematics achievement, and afforded new insights into the content and framework of number sense (Aunio et al., 2004; Chen, Li, \& Yang, 2015; Jones et al., 1996; Jordan et al., 2010, 2007; Markovits, \& Sowder, 1994; McIntosh et al., 1997; Menon, 2004; Reys \& Yang, 1998; Verschaffel et al., 2007; Yang \& Li, 2008). Latterly, the design of number sense diagnostic testing system has often been viewed as a powerful tool for teaching improvement because changes in the teaching of number sense have the potential to transform classroom practice and student learning (Cai, \& Howson, 2013; Chen, Li, \& Yang, 2015).

Assessing and developing number sense for children has been considered as a key issue in mathematics education all over the world (Australian Education Council, 1991; Berch, 2005; Chen, Li, \& Yang, 2015; Common Core State Standards for Mathematics [CCSSM], 2010; Dunphy, 2007; Hong Kong Curriculum Development Council and the Hong Kong Examinations and Assessment Authority, 2014; McIntosh et al., 1997; Ministry of Education in Taiwan, 2008; National Council of Teachers of Mathematics [NCTM], 2000; Yang \& Li, 2008). The new reform-guided mathematics curricula in Hong Kong and Taiwan highlight the importance of number sense in elementary mathematics education because of its potential to develop students' flexible thinking, innovative skills, and the applied ability in the new century. However, few number senses related worked examples are found in the mathematics textbooks used by elementary school students in Hong Kong and Taiwan (Yang, \& Li, 2008; Yang, \& $\mathrm{Li}, 2017)$. This might be partially of the reason [textbook coverage could partially explain overall scores] why both Hong Kong $5^{\text {th }}$ and $6^{\text {th }}$ grade and Taiwan $5^{\text {th }}$ grade students do not perform well on number sense as compared to their performance on international mathematics assessments (e.g. PISA and TIMSS), especially the low percentages on the use of number sense-based method when responding to number sense related questions for the Hong Kong $5^{\text {th }}(33.50 \%)$ and $6^{\text {th }}$ grade $(33.4 \%)$ and Taiwan $5^{\text {th }}$ grade students $(25.57 \%)$. This supports the statement of Stein Stein, Remillard, and Smith (2007) that "curricula differ in significant ways and differences impact student learning" (p. 360). In fact, earlier studies have argued that mathematics textbooks are major resources for providing learning opportunities to students (Cai et al., 2011; Elliot, 2015; Fan, Zhu, \& Miao, 2013; Stein et al., 2007; Tornroos, 2005; Wijaya, van den Heuvel-Panhuizen, \& Doorman, 2015). Textbooks decide what, when and how mathematical content is taught, thereby affecting the learning opportunities provided to students (Reys, Reys, \& Chavez, 2004; Tonroos, 2005). Mathematics textbooks employed in classrooms, in sense of mathematical content, are among the major factors that affect students' opportunities to learn mathematics (Reys et al., 2014; Tarr, Grouws, Chavez, Soria, 2013). Thus, it is reasonable to believe that Hong Kong and Taiwan students do not perform well on number sense test and low percentages on the use of number sense-based method are due to less exposure to number sense activities.

In addition, the means of confidence index are about 4.47 (out of 5) points for HK5, 4.27 points for HK6, and 4.12 points for TW5 students, which are quite high. According to the earlier studies (Hasan, Bagayoko, \& Kelley, 1999; Pesman, \& Eryilmaz, 2010), this indicates that sample students may have significant misconceptions or lack of knowledge related to number sense. In fact, the high confidence index and low number sense performance for the sample students may indicate that these students are overall overconfident and the strong misconceptions exist. Especially, Taiwan $5^{\text {th }}$ grade students have low percentages on number sense first two-tier test that indicates TW5 students have more serious misconceptions than HK5 and HK6 students. Moreover, data revealed Taiwan fifth grade students had strong misconception for 25 out of 40 items that is higher than Hong Kong sixth graders had strong misconceptions for 17 out of 40 items and the Hong Kong fifth graders had strong misconceptions for 18 out 
of 40 items. This supports that Taiwan fifth grade students have more strong misconceptions when responding to number sense related questions than HK5 and HK6 students.

Findings indicate that $\mathrm{HK} 5^{\text {th }}$ and $6^{\text {th }}$ grade students are not only significantly performed better on NS bothtiers test than Taiwan $5^{\text {th }}$ grade students, but also are more confident in answering NS two-tiers test than Taiwan $5^{\text {th }}$ grade students. In addition, findings also reveal that Hong Kong fifth and sixth grade students are better on the use of number sense-based method when responding to number sense related questions than Taiwan fifth grade students. Earlier studies revealed that students' mathematics performance and confidence are closely intertwined (Alves-Martins et al., 2002; Burton, 2014; Gok, 2014), and therefore a higher confidence is predictive of higher performance (Bong \& Skaalvik, 2003). House and Telese (2016) analyzed effects of confidence in mathematics and found that students who have higher confidence about their mathematics ability (e.g., usually do well in mathematics and are good at working out difficult mathematics problems) tend to show higher levels of mathematics achievement. Conversely, students who expressed lower confidence (negative appraisals) of their mathematics ability were more likely to show lower achievement test scores. The findings of this study support the argument that students who have higher confidence on mathematics tend to show higher levels of mathematics performance.

In the meantime, findings reveal that there are 10 and 7 items for HK5 and HK6 students $20 \%$ higher on the correct percentages of number sense first-tier test than the TW5 students. The big differences on the responses to item C3-5 between HK and Taiwan students show that the main misconceptions between Taiwan and Hong Kong students are different. For Taiwan students, the majority of chooses the reason "there are four shaded parts" or "counting four to the right from 0 is 0.4 " or both reasons to explain their choice, while HK5 and HK6 are about onefourths. The options indicate that the students may have wrong concept on the conversion between fraction and decimal so that they percept $\frac{4}{8}$ as 0.4 and $\frac{4}{6}$ as 0.4 . It shows that most Taiwan students are unaware that the denominator needs to be the multiple of 10 to directly convert into decimals. This supports earlier studies that students don't use the representation properly to represent a fraction or decimal or place a number on a number line (Dhlamini, \& Kibirige, 2014; Durkin, \& Rittle-Johnson, 2015). For Hong Kong students, over half choose the correct option, but interestingly most of them choose the wrong reason. They choose the reason "Shaded part is $\frac{4}{8}$ $=0.5$ and the arrow pointing in the picture of the number line is $0.8^{\prime \prime}$. The finding seems contradictory because the HK students showed no conceptual problem on decimal-fraction conversion in the first statement "Shaded part is $\frac{4}{8}=0.5^{\prime \prime}$ but they answered incorrectly for the second statement. Their answer is however rated as high confidence which indicates that the problem is unrelated to lack of training on number line. The contradictory finding needs to be further investigated and while the reason provides no clues on how the students get the result of 0.8 , it is best solved by asking the students on how they come up with the answer. One of the authors' perceptions on the finding is that the students may view the answer by the first instance, in which they carelessly perceive the line as being divided into 5 equal parts instead of 6 . They, therefore, come up with $\frac{4}{5}=0.8$.

In question C3-4, HK students perform significantly better than Taiwan students and HK students shows no apparent misconception on the meaning and addition rule of fraction. For Taiwan students, about one-fourths of them come up with answer $3 \frac{4}{12}$ by adding the denominator and denominator, which implies that they have serious misconception on the meaning of fraction as well as the addition rule of it. Earlier studies found that many students have misconception in fractions (see, e.g., Alghazo, \& Alghazo, 2017; Ashlock, 2006; Education Development Center in USA, 2015; Trivena et al., 2017), such as adding both numerators and denominators (e.g., $1 / 3+2 / 5=3 / 8$ ). It is obvious that some Taiwan fifth grade students do not have profound understanding on adding two fractions. HK students also perform well in this question and the majority of students get the answer with number sense method. Instead of adding the fractions from left to right, these students can skillfully integrate the fractions for easier calculation. Since students are allowed to choose only one reason for their answer, it is possible that some students who are capable of using both correct method to compute the answer choose to play save by choosing the traditional rule-based one. As a result, the students who are using the number sense method may be slightly higher than the finding number.

Question C4-3 reveals very serious misconception on the calculation rule of both HK and Taiwan students. A high percentage of both group of students think that Student A/ Student C is correct. For those who choose Student A, one possible explanation for their misconception is that the rule of "multiplication/division takes precedence over addition/subtraction" is ambiguous and even quite misleading especially in Chinese, which has the literal meaning on the order of calculation as follows: $1^{\text {st }}$ multiplication, $2^{\text {nd }}$ subtraction, $3^{\text {rd }}$ addition, $4^{\text {th }}$ subtraction. As a result, they think that they should first calculate $5 \times 6$. One point to note is that the options "multiplication / division takes precedence over addition/subtraction" and "The bracket makes no difference to the operation" are interrelated. If students hold the thought that multiplication should be done first, then adding the bracket does not affect the answer. If this is what they think, the students are having misconception on the multiplication order rather than the usage of bracket. The students choosing Student C as their answer are probably having 
misconception on the rule of changing the order of multiplication/division.; they fail to acknowledge that the number should follow the sign when changing the order. It is interesting that number of students using the NSbased method to get the right answer is much higher than the rule-based counterpart. It shows that the rule on changing a fraction into the division of two numbers is not commonly aware by both HK and Taiwan students. The findings support the earlier studies that the order of operations regarding Parentheses, Exponents, Multiplication, Division, Addition and Subtraction influenced heavily on students' misconceptions in solving multiplication and division (America's Choice, 2012; Joseph, 2014).

To conclude, HK students perform better on the test than Taiwan students. However, the test reveals that the misconceptions of both groups of students (HK and Taiwan) are dissimilar. This inference matches the fact that the overall performance pattern of HK5 and HK6 students is comparable (their answering preference varies only slightly in each answer choice). This explains that the misconception is constructed not because of school year but of the curriculum/ teaching method. Further studies need to be done to investigate how the presentation of knowledge affect students' acquisition of the math concept and number sense. The authors are also thinking of a possible forth tier (the explanation tier) to investigate some answer choice of students and find out clearly their thinking processes.

In addition, the NSTTT can be easily used by elementary school teachers for the purpose of obtaining the most accurate measure of students' number sense performance, confidence, and misconceptions. Moreover, it can be used to distinguish misconceptions from a lack of knowledge in addition to the advantages of number sense twotier tests. Besides, the NSTTT can be used for monitoring the improvement of instruction because the NSTTT scores are a valid and reliable measure of students' quantitative and qualitative understanding of number sense as well as the ability to examine the confidence level and strong misconceptions.

\section{LIMITATIONS AND FOLLOW-UP FUTURE RESEARCH}

While the 3-tier test is powerful to test whether the majority of students capture key concepts and whether or not they lack the knowledge or having wrong concepts, there are instrumental constraints. The possible "answers" are drawn by guessing the possible misconceptions of the students according to experiences, which does not show the holistic picture on the common misconceptions of all students. The method to which the students draw up their answers may not appear in the answer option. The reliability of the questions can be further strengthened by having some pre-research on the common misunderstanding of math concepts. In addition, the sample is not equally selected which is also a limitation of this study. Therefore, the generalization of the findings from this study should be cautious.

Future research is required to examine questions, such as the following: (1) How can the NSTTT help school teachers view the significance of number sense and related misconceptions? (2) How can the misconceptions found from the NSTTT help school teachers to redesign teaching materials to promote their students' number sense? (3) How can the misconceptions found from the NSTTT help school teachers to review their teaching methods and textbooks used in the classrooms?

\section{REFERENCES}

Akkaya, R. (2016). An Investigation into the Number Sense Performance of Secondary School Students in Turkey. Journal of Education and Training Studies, 4(2), 113-123. https:/ / doi.org/10.11114/jets.v4i2.1145

Alghazo, Y. M., \& Alghazo, R. (2017). Exploring common misconceptions and errors about fractions among college students in Saudi Arabia. International Education Studies, 10(4), 133-140. https://doi.org/10.5539/ies.v10n4p133

Alves-Martins M, Peixoto F, Gouveia-Pereira M, Amaral V, Pedro I. (2002). Self-esteem and academic achievement among adolescents. Educational Psychology, 22(1), 51-62. https:/ / doi.org/10.1080/01443410120101242

America's Choice. (2012). Mathematics navigator: Misconceptions and errors. Retrieved on January 02, 2018 from https:/ / www.westada.org/cms/lib8/ID01904074/Centricity/Domain/207/Misconceptions_Error\%202.p df

Ashlock, R. (2006). Error patterns in computation: Using error patterns to improve instruction. Upper Saddle River, NJ: Pearson/Merrill Prentice Hall.

Aunio, P., Ee, J., Lim, S. E. A., Hautana"kia, J., \& Van Luit, J. (2004). Young children's number sense in Finland, Hong Kong, and Singapore. International Journal of Early Years Education, 12(3), 195-216. https:/ / doi.org/10.1080/0966976042000268681

Australian Education Council. (1991). A national statement on mathematics for Australian school. Melbourne: Curriculum Corporation 
Berch, D. B. (2005). Making sense of number sense: Implications for children with mathematical disabilities. Journal of Learning Disabilities, 38(4), 333-339. https:/ / doi.org/10.1177/00222194050380040901

Bong, M., \& Skaalvik, E. M. (2003). Academic Self-Concept and Self-Efficacy: How Different Are They Really? Educational Psychology Review, 15, 1-40. https://doi.org/10.1023/ A:1021302408382

Burton, L. (2004). Confidence is everything"'-Perspectives of teachers and students on learning mathematics. Journal of Mathematics Teacher Education, 7(4), 357-381. https:/ / doi.org/10.1007/s10857-004-3355-y

Cai, J., \& Howson, G. (2013). Toward and International Mathematics Curriculum. In K. Clements et al. (Eds.), Third International Handbook of Mathematics Education (pp. 949-974). New York: Springer

Cai, J., \& Ni, Y. (2011). Investigating Curricular Effect on the Teaching and Learning of Mathematics in a Cultural Context: Theoretical and Methodological Considerations. International Journal of Educational Research, 50(2), 65-70. https:// doi.org/10.1016/j.ijer.2011.06.002

Caleon, I., \& Subramaniam, R. (2010). Development and application of a three-tier diagnostic test to assess secondary students' understanding of waves. International Journal of Science Education, 32, 939-961. https:/ / doi.org/10.1080/09500690902890130

Cetin-Dindar, A., \& Geban, O. (2011). Development of a three- tier test to assess high school students' understanding of acids and bases. Procedia-Social and Behavioral Sciences, 15, 600-604. https:// doi.org/10.1016/j.sbspro.2011.03.147

Clement, J., Brown, D. E., \& Zietsman, A. (1989). Not all preconceptions are misconceptions: Finding 'anchoring conceptions' for grounding instruction on students' intuitions. International Journal of Science Education, 11(5), 554-565. https:/ / doi.org/10.1080/0950069890110507

Common Core State Standards for Mathematics. (2010). Common Core State Standards for Mathematics. Washington, DC: The National Governors Association Center for Best Practices and the Council of Chief State School Officers. Retrieved on January 02, 2018 from http:/ / www.corestandards.org/the-standards

Dehaene, S. (1997). The Number Sense. New York: Oxford University Press.

Dhlamini, Z. B., \& Kibirige, I. (2014). Grade 9 learners' errors and misconceptions in addition of fractions. Mediterranean Journal of Social Sciences, 5(8), 236-244. https:/ / doi.org/10.5901/mjss.2014.v5n8p236

Dunphy, E. (2007). The primary mathematics curriculum: enhancing its potential for developing young children's number sense in the early years at school. Irish Educational Studies, 26(1), 5-25. https:/ / doi.org/10.1080/03323310601125088

Durkin, K., \& Rittle-Johnson, B. (2015). Diagnosing misconceptions: Revealing changing decimal fraction knowledge. Learning and Instruction, 37, 21-29. https:/ / doi.org/10.1016/j.learninstruc.2014.08.003

Dyson, N. I., Jordan, N. C., \& Glutting, J. (2013). A number sense intervention for low-income kindergartners at risk for mathematics difficulties. Journal of Learning Disabilities, 46(2), 166-181. https:/ / doi.org/10.1177/0022219411410233

Education Development Center in USA. (2015). Eliciting Mathematics Misconceptions. Retrieved on January 02, 2018 from

http://em2.edc.org/sites/default/files/assessmentfiles/EM2_Fractions_Adding_and_Subtracting_ALL.p df

Elliot, S. N. (2015). Measuring opportunity to learn and achievement growth: key research issues with implications for the effective education of all students. Remedial $\mathcal{E}$ Special Education, 36(1), 58-64. https:/ / doi.org/10.1177/0741932514551282

Fan, L., Zhu, Y., \& Miao, Z. (2013). Textbook Research in Mathematics Education: Development Status and Directions. ZDM, 45(5): 633-646. https:/ / doi.org/10.1007/s11858-013-0539-x

Gersten, R., Jordan, N. C., \& Flojo, J. R. (2005). Early identification and intervention for students with mathematics difficulties. Journal of Learning Disabilities, 38(4), 293-304. https:/ / doi.org/10.1177/00222194050380040301

Gok, T. (2014). Students' achievement, skill and confidence in using stepwise problem-solving strategies. Eurasia Journal of Mathematics, Science \& Technology Education, 10(6), 617-624. https://doi.org/10.12973/eurasia.2014.1223a

Griffin, L. B. (2016). Tracking decimal misconceptions: Strategic instructional choices. Teaching Children Mathematics, 22(8), 489-494. https:/ / doi.org/10.5951/teacchilmath.22.8.0488

Hasan, S., Bagayoko, D., \& Kelley, E. L. (1999). Misconceptions and the certainty of response index (CRI). Physics Education, 34, 294-299. https:/ / doi.org/10.1088/0031-9120/34/5/304 
Hong Kong Curriculum Development Council and the Hong Kong Examinations and Assessment Authority. (2014). Mathematics Education Key Learning Area - Mathematics Curriculum and Assessment Guide (Secondary 4 6). Hong Kong: Authors.

House, J. D., \& Telese, J. A. (2016). Achievement of eighth-grade students in Korea on the TIMSS 2011 Assessment: Effects of confidence in mathematics and engagement in mathematics lessons. Education, 137(1), 77-81

Jones, G. A., Thornton, C. A., Putt, I. J., Hill, K. M., Mogill, A. T., Rich, B. S., \& Van Zoest, L. R. (1996). Multidigit number sense: A framework for instruction and assessment. Journal for Research in Mathematics Education, 27, 310-336. https://doi.org/10.2307/749367

Jordan, N. C., Glutting, J., \& Ramineni, C. (2010). The importance of number sense to mathematics achievement in first and third grades. Learning and Individual Differences, 20(2), 82-88. https:/ / doi.org/10.1016/j.lindif.2009.07.004

Jordan, N. C., Glutting, J., Ramineni, C., \& Watkin, M. W. (2010). Validating a number sense screening tool for use in kindergarten and first grade: Prediction of mathematics proficiency in third grade. School Psychology Review, 3(2), 181-195.

Jordan, N. C., Kaplan, D., Locuniak, M. N., \& Ramineni, C. (2007). Predicting first-grade math achievement from developmental number sense trajectories. Learning Disabilities Research $\mathcal{E}$ Practice, 22(1), 36-46. https:// doi.org/10.1111/j.1540-5826.2007.00229.x

Joseph, K. N. (2014). College students' misconceptions of the order of operations. Fredonia, NY: Department of Mathematical Sciences, State University of New York

Lin, Y. C., Yang, D. C., \& Li, M. N. (2016). Diagnosing Students' Misconceptions in Number Sense via a Web-Based Two-Tier Test. Eurasia Journal of Mathematics, Science $\mathcal{E}$ Technology Education, 12(1), 41-55. https://doi.org/10.12973/eurasia.2016.1420a

Markovits, Z., \& Sowder, J. T. (1994). Developing number sense: An intervention study in grade 7. Journal for Research in Mathematics Education, 25(1), 4-29. https:/ / doi.org/10.2307/749290

McIntosh, A., Reys, B. J., \& Reys, R. E. (1992). A proposed framework for examining basic number sense. For the Learning of Mathematics, 12, 2-8.

McIntosh, A., Reys, B. J., Reys, R. E., Bana, J., \& Farrel, B. (1997). Number sense in school mathematics: Student performance in four countries. Mathematics, Science, and Technology Education Centre, Edith Cowan University.

Menon, R. (2004). Elementary school children's number sense. International Journal for Mathematics Teaching and Learning. Retrieved on January 08, 2018, from http:/ / www.cimt.plymouth.ac.uk/journal/ramamenon.pdf

Ministry of Education in Taiwan. (2017). Twelve-year joint mathematics curricula plan in Taiwan. Taiwan: Taipei. (In Chinese).

Mullis, I. V. S., Martin, M. O., Foy, P., \& Hooper, M. (2016). TIMSS 2015 International Results in Mathematics. Retrieved on from Boston College, TIMSS \& PIRLS International Study Center website: http:/ / timssandpirls.bc.edu/timss2015/international-results/

National Council of Teachers of Mathematics (NCTM). (1989). Curriculum and evaluation standards for school mathematics. Reston, VA: NCTM.

National Council of Teachers of Mathematics (NCTM). (2000). The principles and standards for school mathematics. Reston, VA: NCTM.

Organization for Economic Co-operation \& Development (OECD). (2016). PISA 2015 Results in Focus. Paris: OECD.

Pesman, H., \& Eryilmaz, A. (2010). Development of a three-tier test to assess misconceptions about simple electric circuits. The Journal of Educational Research, 103, 208-222. https:/ / doi.org/10.1080/00220670903383002

Resnick, L. B. (1989). Defining, assessing and teaching number sense. In Sowder \& Schappelle (Eds.), Establishing foundations for research on number sense and related topics: Report of a conference. San Diego, CA: San Diego State University, Center for Research in Mathematics and Science Education.

Reys, B. J. (1994). Promoting number sense in middle grades. Teaching Mathematics in the Middle School, 1(2), 114120.

Reys, B. J., Reys, R. E., \& Havez, O. (2004). Why Mathematics Textbooks Matter. Educational Leadership, 61(5), 61-66.

Reys, R. E., \& Yang, D. C. (1998). Relationship between Computational Performance and Number Sense among Sixth- and Eighth-Grade Students in Taiwan. Journal for Research in Mathematics Education, 29(2), 225-237. https:/ / doi.org/10.2307/749900

Şengül, S., \& Gülbağc1, D. H. (2012). Evaluation of number sense on the subject of decimal numbers of the secondary stage students in Turkey. International Online Journal of Educational Sciences, 4(2), 296-310. 
Şengül, S., \& Gülbağcı, D. H. (2014). The strategies of mathematics teachers when solving number sense problems. Turkish Journal of Computer and Mathematics Education (TURCOMAT), 5(1), 73-88. https://doi.org/10.16949/turcomat.67936

Sood, S., \& Jitendra, A. K. (2007). A comparative analysis of number sense instruction in reform- based and traditional mathematics textbooks. Journal of Special Education, 41(3), 145-157. https:/ / doi.org/10.1177/00224669070410030101

Sowder, J. (1992). Estimation and number sense. In D.A. Grouws (Ed.), Handbook of research on mathematics teaching and learning (pp. 371-389). New York, NY: Macmillan.

Stein, M., Remillard, J., \& Smith, M. (2007). How Curriculum Influences Student Learning. In F. Lester, Handbook of Research on Mathematics Teaching and Learning (pp. 319-369). Greenwich, CT: Information Age.

Tan, K. C. D., Goh, N. K., Chia, L. S., \& Treagust, D. F. (2002). Development and application of a two-tier multiple choice diagnostic instrument to assess high school students' understanding of inorganic chemistry qualitative analysis. Journal of Research in Science Teaching, 39(4), 283-301. https:/ / doi.org/10.1002/ tea.10023

Tarr, J. E., Grouws, D. A., Chávez, Ó., \& Soria, V. M. (2013). The effects of content organization and curriculum implementation on students' mathematics learning in second-year high school courses. Journal for Research in Mathematics Education, 44(4), 683-729. https:/ / doi.org/10.5951/jresematheduc.44.4.0683

The Hong Kong Curriculum Development Council. (2000). Learning to learn: The way forward in curriculum development. Hong Kong: Author.

The Hong Kong Curriculum Development Council. (2014). Mathematics Education Key Learning Area. Hong Kong: Author. Retrieved on January 2018 from http://334.edb.hkedcity.net/doc/eng/curriculum/Math\%20C\&A\%20Guide_updated_e.pdf

The Hong Kong Curriculum Development Council. (2017). Mathematics Education Key Learning Area Curriculum Guide (Primary 1 - Secondary 6). Hong Kong: Author. Retrieved on January 08, 2018 from http://www.edb.gov.hk/attachment/en/curriculumdevelopment/renewal/ME/ME_KLACG_eng_draft_2017_04.pdf

Törnrros, J. (2005). Mathematics Textbooks, Opportunity to Learn and Student Achievement. Studies in Educational Evaluation, 31(4), 315-327. https:/ / doi.org/10.1016/j.stueduc.2005.11.005

Trivena, V., Ningsih, A. R., \& Jupri, A. (2017). Misconception on addition and subtraction of fraction at primary school students in fifth-grade. Journal of Physics: Conference Series, 895(1), 1-7. https:/ / doi.org/10.1088/17426596/895/1/012139

Verschaffel, L., Greer, B., \& De Corte, E. (2007). Whole number concepts and operations. In F. K. Lester, Jr. (Ed.), Second handbook of research on mathematics teaching and learning (pp. 557-628). Charlotte, NC: Information Age.

Wijaya, A., Van den Heuvel-Panhuizen, M., \& Doorman, M. (2015). Opportunity-to-learn Context-based Tasks Provided by Mathematics Textbooks. Educational studies in Mathematics, 89, 41-65. https:/ / doi.org/10.1007/s10649-015-9595-1

Yang, D. C. (2003). Teaching and Learning Number Sense - An Intervention Study of fifth grade students in Taiwan. International Journal of Science and Mathematics Education, 1(1), 115-134. https://doi.org/10.1023/A:1026164808929

Yang, D. C., \& Li, M. N (2013). Assessment of Animated Self-Directed Learning Activities Modules for Children's Number Sense Development. Journal of Educational Technology and Society, 16(3), 44-58.

Yang, D. C., \& Li, M. N. (2017). A study of fifth graders' performance on the three-tier number sense test. Paper presented at the $41^{\text {st }}$ Annual Meeting of the International Group for the Psychology of Mathematics Education, Singapore, July 17-22, 2017.

Yang, D. C., \& Wu, W. R. (2010). The study of number sense realistic activities integrated into third-grade math classes in Taiwan. The Journal of Educational Research, 103(6), $379-392$. https:/ / doi.org/10.1080/00220670903383010

Yang, D. C., Li, M. N., \& Lin, C. I. (2008). A Study of the Performance of 5th Graders in Number Sense and its Relationship to Achievement in Mathematics. International Journal of Science and Mathematics Education, 6(4), 789-807. https:// doi.org/10.1007/s10763-007-9100-0

\section{http://www.ejmste.com}

